\title{
Sustainable development, environmental safety and water management as quality of life indicators
}

\author{
Abdalsalam Ahwaila \\ Phd, candidate \\ DOI: 10.29322/IJSRP.11.10.2021.p11882 \\ http://dx.doi.org/10.29322/IJSRP.11.10.2021.p11882
}

\begin{abstract}
Environmental security is addressed at the international level. Peace, national security and human rights depend on it. As such, it encapsulates: "the relationship between the human population and natural resources." That is why the focus of national security is on it. When environmental safety is achieved, then protection from several types of hazards is achieved (both from natural and human factors, and due to inadequate management, accident or ignorance).

In this way, possible damage to flora and fauna by the human factor is reduced, and both locally and globally, "protection of people, natural and material goods" is ensured. Some of the key threats to environmental security would be: due to human factors (activities), threats to the environment, obvious and less obvious consequences that can cause environmental change, threats to groups, individuals, humanity posed by contamination, global warming, water scarcity.
\end{abstract}

Index Terms- quality of life, sustainability, indicators, water management

\section{INTRODUCTION}

$\mathrm{P}$ rosperity, ie its characteristics that were immediately accepted (such as solidarity, freedom, equality, but also social capital), were not tested empirically. Therefore, more common (concepts dating back to 1990) are those concepts that imply well-being as a social quality, comprehensively speaking. The quality of life reveals whether and to what extent the local population is (un) satisfied with its basic needs and aspirations, but also how much they are (un) satisfied with some aspects of life. It also refers to the positive effects on people, and especially on health: "physical and mental". ${ }^{1}$ Quality of life would be the degree of satisfaction of human needs (social, spiritual and material). This concept includes personal, then national security, and economic and political freedoms, but also a clean environment. When viewed from the social level, it is observed how much a society has reached the quality of life, both comprehensively and in certain aspects. The

${ }^{1}$ Campbell, A.,(1973). Aspiration, Satisfaction, and Fullfilment, In: A. Campbell, Ph. Converse (eds). The human meaning of social change. New York. Russell Sage.p. 441-446

${ }^{2}$ Campbell, A.,(1973). Aspiration, Satisfaction, and Fullfilment, In: A. Campbell, Ph. Converse (eds). The human meaning of social change. New York. Russell Sage.p. 441-446

This publication is licensed under Creative Commons Attribution CC BY.

http://dx.doi.org/10.29322/IJSRP.11.10.2021.p11882 living conditions of an individual can give us valuable information in relation to the above.

\section{Quality of life as mesure of sustainability}

From sustainability to quality of life, if achieved, to a certain extent. When we talk about sustainability, its importance is recognized at the same time as the recognition of "well-being as a social quality" (since 1990). ${ }^{2}$ Sustainability implies completely new forms of decision making. This would mean abandoning the former classical approach, in favor of an approach that advocates development in which social and economic progress does not take place at the expense of ecology.

This approach has outgrown the regional and national level, as it has become crucial at the planetary level. We have already emphasized in earlier chapters that the essence of sustainability is to maintain the existing economic development, ie to avoid regression, and then to continue in the direction of ensuring the standard of living of citizens. If this is how efforts are directed in society, natural capital can be preserved.

The ideal type of development would be if unhindered progress without regress and without discontinuity would be ensured through sustainability, so the imperative of sustainable development would be fully respected. However, in reality, this is a little harder to achieve in the sense that, unfortunately, any development is accompanied by either wars or a drastic disturbance of the equilibrium that rules the environment. Sustainability in the social sense concerns first of all respect for labor rights (with an emphasis on women's labor rights), then respect for human rights. It is crucial that new generations have even easier access to society's resources than previous ones. It is about avoiding (as much as possible), exclusion, marginalization of certain social groups, but to make life available to all in which they will feel the purpose of their life engagement, to have optimal health, which gives them the opportunity to they are engaged and that it is unquestionable for the generations to come. It will depend (above all) on the social, economic and environmental aspects, because they "pull society in a progressive direction, although it can be the opposite direction, depending on the chosen activities."

3 Law, M.J.K. (2009). Factors Affecting Sustainability Development: High-Tech Manufacturing Firms in Taiwan. Asia Pacific Management Review Vol 15(4) (2010), p. 619-633 
Sustainable development strives to improve the quality of life, through strategic planning, for a longer period of time. By definition, it is a development: "that meets the needs of the present without compromising the ability of future generations to meet their own needs."

\section{Indicators of sustainable developement}

In order to have an insight into the quality or speed of that progress, certain indicators are necessary. The first ones proposed by the United Nations were those that referred to several areas (institutional, for which 15 indicators were proposed, for economic 23, environmental 55 and social area 41 indicators). So, in the beginning (in 1995), the proposal contained a handful of indicators (as many as 96 with 43 indicators, and by UNOECD). Over time (in 2000.), this package was reduced to a much smaller number (only 52 indicators). They are used to measure the shift or regression in relation to sustainable development.

The importance of indicators needs to be perceived in the right way, because if they are established adequately, they provide important guidelines, whether a particular development or undertaken project leads to sustainable development or not. Therefore, (from 2000 to 2001) additional indicators were introduced, as an integral part of the indicators of sustainable development (the so-called SD index), (within the Millennium Project or the Global Partnership). ${ }^{5}$ If there are no valid indicators, it is not feasible to set a strategic framework for sustainable development, nor to monitor it in an appropriate way. However, great progress followed, after such a change in 2012 in Rio and adoption of Agenda 2030, where we finally started talking about socially responsible companies, which until then did not bear any responsibility or were called by state administrations, which were not yet in the job description, to find solutions. , in line with their social engagement, a good economic base based on profit, to, in addition to making a profit, return something to the community in which they operate. So, to "be socially responsible, as they have never been before." 6 Today, the term sustainable development is already ingrained. No one questions its importance anymore, especially the "obligation of companies to operate as socially responsible."7 The focus is on something more complex: will this positive turn really yield results, is it too late for humanity when it comes to the above parameters, and not just unprecedented climate change.

\section{Tasks of sustainable developement}

Sustainable development, therefore, implies such a broader concept, about which there is no longer a dilemma. We are also witnesses of the mentioned climate changes, which also leave us without a doubt, when it comes to the urgency of changes in the environmental field. Thus, the main task of sustainable development, and when it comes to environmental parameters, is

\footnotetext{
${ }^{4}$ The World Commission on Environment and Development. (1987). Our Common Future. Oxford. Oxford University Press UNEP. p. 11

${ }^{5}$ Sachs, D. D. (2015). Achieving the Sustainable Development Goals. Journal of International Business Ethics, Vol. 8 No. 2

${ }^{6}$ Wals, A.E.J. and Schwarzin, L. (2012) Fostering organizational sustainability through dialogic interaction, The Learning Organization, Vol. 19 Iss: 1, p.11 - 27.
}

to provide the greatest possible protection of natural resources, because in that way, especially resources are protected without which food production (forests, soil, water sources) would not be feasible.

So, some of the causes that have influenced sustainable development to deal with ecology since its inception are now more tangible than then. Only now is the justification for such a starting point increasingly visible. Also, the connection between the natural and social dimensions in the concept of sustainable development, ie in its ecological parameter, is becoming clearer. Sustainability is, in essence, providing urgent responses to threatening changes, but taking care not to jeopardize the potential for sustainable development, both for present and future generations. For this purpose, it is necessary to take care of the use of non-renewable sources so as to enable their long-term, wise exploitation, with knowledge of their limitations, but we can also replace them with those that are renewable and whose exploitation is safe for a certain time interval. , and those hazardous materials must be used so that they do not exceed their range of toxicity. Most of all, care must be taken not to cross the red line, because that would mean "a path without return."

Furthermore, it is necessary to establish a management system that will take into account the ecology (not to cross the mentioned red line and to maintain the diversity of the environment). Also, stop forcing the economic parameter, within sustainable development, to the detriment of others, and related to some of the topics. Then, the application of indicators, to monitor the situation on the ground. Insisting on a comparative emphasis on both the social and the natural, in order to improve the quality of life. Finally, coordinating all these activities at the same time in order to get the best results in the application of the above. As we have already emphasized before, it is necessary to raise the whole process and the institutional level, in order to get the results as soon as possible. Importance of environmental safety as a component of population safety is an important element of the concept of sustainable development. The focus on population security is (human development within the concept of sustainable development), within the concept of "three columns" (ecology, economy, society).

\section{Global efforts}

When we talk about the current situation, the times in which we live, this aspect of environmental safety is becoming more complicated every day. There are great fears at the planetary level, because of the changes in this area, namely, their unpredictability and increasing scope, have exceeded expectations, and it seems that there may be a turnaround in this sense, which, despite so much effort towards sustainable development, will still lead until the red line is crossed. To this end, it is necessary to establish coordination on a broader scale, globally, where certain processes

\footnotetext{
${ }^{7}$ Epstein, M.J. and Buhovac, A.R. (2010). Solving sustainability implementation challenges. Organizational Dynamics, Vol. 39: p. 306-315

8 Moldan, B., Janoušková, S. and Hák, T. (2011). How to understand and measure environmental sustainability: Indicators and targets. Ecological Indicators, Vol. 17, p.4-13
} 
will be monitored and information exchanged, in order to prevent such a dangerous outcome. When the growing usurpation of the terrain by human hands is taken into account, it unfortunately leads to changes that do not only concern that specific area, but are reflected in a wider area, changing the previously established ecosystem (biodiversity), which changes the predispositions for food supply. quality and quantity), but the whole space also changes, which calls into question the further survival of flora and fauna. ${ }^{9}$

Thus, the human factor can be crucial, there can be certain consequences (hidden or obvious) for environmental changes, but also for the human factor (individuals, entire groups or for humanity as a whole), and they relate to environmental threats of the latest type (lack of water, contamination or warming). A certain level of security is achieved when there is equal access to all existing resources, and when there is coordination between society and the ecological system, but also when it is possible to get out of certain crisis situations using mechanisms provided for conflict situations, which are caused by crisis episodes. ecological type. In that way, it is possible to protect resources from nature, to protect both public and social, as well as the interests of citizens, from these threats ${ }^{10}$ (for individuals, entire groups or for humanity as a whole, or for the existing flora and fauna, as appropriate).

\section{Quality of life and ecology}

Comparing quality of life concepts with sustainability, as also a key concept, we must emphasize that the distinction is that the former is based on the level of the individual, ie how that individual (does not) enjoy well-being at the current moment of his life. property, ie striving to establish equality, not only when it comes to resources, but the right to enjoy a healthy environment, and all social property, by all citizens of that society. There are still dilemmas among some experts, as well as for the stated ambiguity when it comes to crucial indicators of quality of life, whether it is possible to achieve optimal sustainability in one society and at the same time achieve quality of life, and whether it should be classified as sustainable. development or vice versa. This dilemma is clarified by explaining that sustainability is a concept that has a broader meaning, because it refers to the whole society, in the long run, while the quality of life is focused on the lives of individuals, and in the short term, therefore, at the moment. So it became completely clear.

When we talk about the quality of life from ecology perspective, then there are certain deteriorations on the ecological level, which ruin the quality of life. Worsening is mentioned in two ways. First, it may be due to the lack of certain services, so citizens are, in this case, deprived of certain benefits that they should have in their lives and which significantly impairs the quality of their lives. The second is when there are certain benefits but they are not at a satisfactory level, so that in this way they ruin the quality of life (transport, proper waste disposal, drainage, sanitary systems, water...).

\section{Economic developement and water ecology}

\footnotetext{
9 Birmingham, D. (1995). "The Decolonization of Africa". Routledge. London. p.50

${ }^{10}$ Gaddis, J. L. (2004). "Surprise, Security and the American Experience”. Harvard University Press, Cambridge. p.130.
}

In circumstances when the mentioned benefits are not at the appropriate level, then there is a great danger for citizens in the form of possible contamination, which can be detrimental to their health. This is a sign that the level of infrastructure and services of the ecological type is really not appropriate. Then it is to be expected that soil regression will follow, and other types of contamination may occur.

In order to achieve the concept of sustainable development, which can then go further in the direction of raising the quality of life, it is necessary to work at the international level, above all, to reduce poverty, and in accordance with the decisions (from 2000, the United Nations summit), which set it as the ultimate goal, because it depends on that, and only then on the rest of what we have stated, whether sustainable development, and only then the quality of life will be achievable. Namely, the states have committed themselves at the international level to work together, "in order to reduce poverty, to the extent of its eradication at the planetary level."11 When we talk about the quality of life, the indicator (HDI-Human Development Index, United Nations) is in force, which refers to both the quality itself and the degree that the state has achieved in its development. It relies on several indicators (education, gross domestic product per capita, and life expectations).

When economic development in a society is optimal, and especially on the rise, then conditions are created for thinking about ecology in advance, for certain solutions to be sought proactively, so we do not wait for the last moment. In such companies, it is then possible, thanks to the legislation, to impose certain obligations on companies to be responsible not only to their shareholders, but also to strive only and exclusively for profit. They, then, become responsible before the company in which they make a profit, to use and introduce certain patents, which protect the environment from various forms of contamination (wastewater, air pollution by toxic gases, etc.). That is, to take care, in the best case and without legal coercion, to implement such measures, before the need for them arises.

Within the concept of sustainable development, water should be consumed in a restrained and planned way. This means that strategic planning should be planned in order to achieve controlled water use, in line with shortages, which are increasingly occurring in various regions and parts of the planet, so as to avoid unnecessary waste, by introducing technological innovations, which achieve maximum efficiency. These would be completely new methods, which are in line with the mentioned concept of sustainable development with the desire to achieve the concept of quality of life. This is important because water as a resource is irreplaceable, and if there is a lack of water, changes occur in the entire ecosystem that cannot be easily returned to the starting position. It is closely connected with the famous red line, which is a sign of alarm, a road to an irreversible state. In the times in which we live, it is increasingly difficult to reach the concept of sustainable development, because water shortages are becoming more frequent and greater. In addition, there are problems with rapid urbanization, high natural growth and increased

11 Vlavianos-Arvanitis, A., Keles, R., (2010). "Biopolis: An Urban Development Model. Networking, Education, and Culture". Paper presented to International Ekistics Conference on Human Settlements. Mumbai. p.4. 
industrialization, urbanization, which only exacerbate the "problem of water scarcity."12

\section{Conclusion}

Modern instruments have also been developed that can be used preventively, predicting future conflicts caused by water resources. We also want to meet the local population in terms of assistance from rich countries, poor countries, to build their "governance systems on the principles of sustainability, which will strengthen them and protect them from potential conflicts in the future." ${ }^{13}$ It is important to know that in some from the countries, the political elites themselves do not allow the creation of a realistic image from the field, thus protecting their interests on the local level, as inviolable (that is why readings will be made remotely).
Some of the institutes are extremely committed to this issue on an ongoing basis (Danish Institute for International Studies since 2007). The point is to conclude that field intervention is more crucial than predisposition on the ground, which, if adequate and timely, can solve the problem even before it begins (a potential conflict existed at the end of the last century in Egypt, then in Jordan, but has been overcome, thanks to the political leaders of these two countries).

\section{AUTHORS}

First Author - Abdalsalam Ahwaila phd, candidate
12 Alghariani, S.A. (2003). Water transfer versus desalination in North Africa sustainability and cost comparison. Libyan Studies Journal.
13 Law, M.J.K. (2009). Factors Affecting Sustainability Development: High-Tech Manufacturing Firms in Taiwan. Asia Pacific Management Review Vol 15(4) (2010), p. 619-633 